\title{
A NZCTU perspective: employment relations during and beyond the 2017-2020 Coalition Government
}

\author{
RICHARD WAGSTAFF*
}

\section{Introduction/Preamble}

After nine years of a National-led government, and with it a policy slanted toward business' and away from workers' interests, the Council of Trade Unions (CTU) welcomed a change to a new Coalition Government in 2017. There had been many changes to laws over the period of the previous government that affected the work of unions and conditions of employment that unions did not support and were eager to change. We were keen to roll back the negative amendments to employment law that had been put in place, as well as advance and improve in new areas. Of course, changes to the laws affecting employment are one thing, but the government also has an impact through the policies and activities of its agencies: as a direct employer, in procurement and as a regulator. Taken together, there certainly was an improvement over the past three years for unions and workers, but it was interrupted somewhat due to the extraordinary circumstances of a pandemic, which required an urgent and immediate response and was prioritised above all else. Below are some of the more significant changes.

\section{What we liked....}

\section{Legislative Priorities}

\section{Pay Equity}

The Ardern Government inherited poorly drafted pay equity legislation, which had been introduced into the house just before the 2017 election, with strong reservations from the CTU. In particular, the CTU was concerned that the Bill restricted access to appropriate comparators in the assessment phase of reaching a pay equity settlement and did not provide sufficient support for collective bargaining. The new government reconvened the tripartite Joint Working Group on Pay Equity which unanimously recommended the removal of comparator restrictions and made other recommendations to improve the process of raising and settling a claim. With CTU support, the government prioritised concluding the legislation, and the new Equal Pay Amendment Act 2020 was passed in July 2020, reflecting the reconvened Joint Working Group recommendations and promoting collective bargaining as a primary means of negotiating and settling claims for groups of underpaid women, under the shadow of compulsory arbitration if the parties fail to reach agreement. Significantly, the Act follows aspects of the 'Hobbit Law' reform and Fair Pay Agreements in that it effectively provides for the establishment of minimum standards for particular workforces, over and above which bargaining takes place, and within a framework that involves arbitration if necessary.

\footnotetext{
* President, New Zealand Council of Trade Unions (NZCTU) Te Kauae Kaimahi; PO Box 6645, Wellington, New Zealand
} 


\section{Employment Relations Act 2000 Amendments}

The CTU advocated for an immediate roll back of the negative amendments that the Key Government had made to the Employment Relations Act 2000 (ERA). We sought a return of the ERA as it was prior to the 2008 election, and this was achieved with the passing of the Employment Relations Amendment Act (ERAA) in 2018. These amendments were important and included a series of changes that enabled unions to more effectively gain access to the workplace and obtain information, better negotiate and conclude settlements of collective agreements, including multi- employer collective agreements, take industrial action, restore the right to take rest and meal breaks, protect vulnerable workers in change, and restore some rights to reinstatement for unfair dismissals.

All of these changes were strongly supported by the CTU. We had also sought to remove altogether the law supporting 90-day trial periods, which allow employers to 'fire at will', and create a vulnerable employment relationship for new workers. They have been widely deployed with devastating consequences for many workers trying to get secure employment, while not creating any additional employment. While we were successful at removing trial periods for workplaces with greater than 20 employees, we were disappointed not to remove them altogether, and remain committed to removing them for all workplaces.

\section{Fair Pay Agreements}

More fundamental reform than simply winding back National's ERA amendments was and is required. Despite the ERA's aim to promote collective bargaining, in practice the Act never really returned New Zealand's industrial relations to a state where all workers had the opportunity to truly freely associate and collectively bargain. The reality remains that, for most workers, employment conditions are set through individual employment agreements established unilaterally by the employer, with no union presence in the workplace or at the bargaining table. Until more fundamental changes occur to our industrial relations legislative framework, it is unlikely that this situation will significantly change, and ongoing low union density will remain, especially in the private sector.

Well before the general election in 2017 , and recognising the inadequacy of the statutory minimums, the CTU advocated the establishment of negotiated Industry Standards of basic terms and conditions for specific industries and occupations across the economy. Our purpose was to create a floor above which individual and collective bargaining would still take place. We argued that the Care and Support Pay Equity Settlement was, in many respects, already an example of an industry standard operating across the residential aged care and disability and home support sectors.

The government agreed to advance this idea and established the Fair Pay Agreement Working Group (2018), comprised of union, business, legal and academic representatives, and chaired by former National Prime Minister, Jim Bolger, which reported back a set of recommendations at the end of 2018 in a report entitled "Fair Pay Agreements - Supporting workers and firms to drive productivity growth and share the benefits". The Working Group grappled with the challenges of embedded low wages and low productivity in New Zealand, and looking to international best practice, recommended the establishment of Fair Pay Agreements that conceptually were very much in line with the CTU's thinking on industry standard agreements. Essentially, the Working Group recommended the establishment of minimum standard 
agreements across industries and occupations, negotiated by employers and unions, and fixed by arbitration if agreement could not be reached. While Business New Zealand supported the recommendations, they had a major caveat - that the process should be voluntary, which would effectively render their introduction as meaningless. Despite expectations that this report would be translated into law, it did not get that far and remains supported by Labour and the Greens as a priority of business in the next term of government. The following were influential in these discussions: OECD (2017; 2018), Rosenberg (2017a), Nana (2019), MBIE (2018; n.d),

\section{Hobbit Law}

Another urgent priority was correcting the legislation introduced, again, by the Key Government in relation to the film industry, known by many of us as the 'Hobbit Law' which removed the rights of film industry workers to collective bargaining and other labour rights of employees. A Film Industry Working Group (2018a) composed of industry and business representatives, and CTU and worker representatives was established in January 2018, with Terms of Reference designed to create recommendations that would enable collective bargaining for all workers engaged in, what later become referred to as the 'screen' rather than 'film' industry, while also enabling workers to remain as contractors or become employees by agreement. The Working Group (2018b) made a set of recommendations that had unanimous support of the group that broke new ground by enabling the establishment of collectively bargained industry or occupational minimum standards that would apply to all those engaged as contractors in the industry. While the right to strike was not permitted in the recommendations, it was agreed that if agreement could not be reached, compulsory arbitration would take place to settle disagreements. For those engaged as employees, normal employment rights would be applied. This was a significant outcome because it had unanimous support, introduced collective bargaining for contractors, and introduced compulsory arbitration. It was also complex translating these concepts into law and was not completed in this term of government.

\section{Paid Parental Leave}

The Parental Leave and Employment Protection Amendment Bill was passed to extend the duration of paid parental leave (from 18 weeks) to 26 weeks by 2020 , which had been the focus of union campaigns and was warmly welcomed by the union movement. The new law also increased 'Keeping in Touch' days from 40 hours to 64 hours, allowing parents to do limited work while on parental leave if they choose to.

\section{Non-Legislative Significant Developments and Issues}

\section{Tripartism and the Future of Work}

The establishment of the Future of Work Tripartite Forum has seen a welcome return to tripartism, where the social partners - government, unions and business - work together to resolve challenges to work created by technological change, climate change, globalisation and demographic change. The Finance Minister begun this process pre-election when, in opposition, he led a Future of Work Commission which was reported in November 2016, after extensive dialogue involving unions and business. Once in government as the Finance Minister, the Hon. Grant Robertson pulled together a tripartite Future of Work Forum, which met roughly every quarter, had a rotating chair between the parties - government, CTU and Business NZ and focussed on four broad areas of work: Industry Transformation Plans, support for displaced 
workers, in-work training and protections for non-standard workers. This forum gathered pace and has been successful at achieving consensus and buy-in by the social partners on important policy areas, and active policy development. There is much work to do, and a continued focus on creating good work is essential if we are to be successful. Work on areas like industry policy is a welcome and significant development in thinking that has been effectively dormant for decades.

Related to this has been the focus on Just Transition, and the need to move out of old (especially carbon-based) industries, into greener, cleaner, and more productive industries. The decision to halt prospecting in Taranaki, and the subsequent Just Transition exercise, led by central and local governments, has been welcomed enthusiastically by the CTU and affiliates (CTU, 2015; Future of Work Tripartite Forum, (2019); ILO, (2019).

\section{Reform of Vocational Education (ROVE)}

With support from the CTU, the Education Minister, Chris Hipkins, embarked on a major project of reform of Vocational Education to create a unified system across on-job and off-job learning. Once the transition period is complete, the reforms promise to end wasteful competition between providers by creating a single national Institute of Skills and Technology. CTU affiliates, including the Tertiary Education Union (TEU), supported this move as a necessary reform of the failed market model of tertiary education in which public institutions were expected to compete with each other as well as with private providers. This had led to perverse outcomes, with many institutions duplicating each other's course offerings to compete for students in the major centres, while institutions in the regions struggled to remain financially viable, creating constant uncertainty for their staff, students and communities.

In the new model of vocational education, a strong network of regional provision will be maintained and connected to the employment and learning needs of each region, including through the advice of Regional Skills Leadership Groups with representation of local employers and unions. The national Institute will also take on the role of coordinating in-work training, while industries will have a strengthened voice at the national level in defining the learning outcomes required, with employers and unions represented on six Workforce Development Councils.

\section{Health and Safety}

The Key Government had responded to the Pike River tragedy by creating the new Health and Safety at Work Act (HSWA) and a new Agency - WorkSafe - as the regulator. Since the introduction of the HSWA, a range of supplementary regulations continued to be implemented, these focus on specific topics such as hazardous substances, mining and working with plant.

The CTU broadly supported the new HSWA and the creation of WorkSafe, though we remain critical of the lack of support for effective worker participation, particularly health and safety representatives in the law, and the lack of capacity and capability at WorkSafe, particularly in relation to the regulatory and prosecution functions of WorkSafe. These concerns remain despite increases in resourcing. While in the workplace, unions would like better engagement with WorkSafe, at a national level they have engaged with the CTU effectively and supported our call for greater worker participation in all things health and safety. The agency has also been publishing guidance on the duties and rights of the various parties in the workplace. More 
recently, WorkSafe has signalled an intent to promote a more holistic view of work, and the need to create better work, including better dialogue with workers and their representatives.

These are all positive and supported developments, but the fact remains that New Zealand continues to have a very poor health and safety record compared to countries like ours, and despite best efforts, there has not been enough progress. Part of this reflects the top down nature of management practice embedded in many New Zealand workplaces that do not support worker and union voice, and part of it reflects the fact that WorkSafe desperately needs more resourcing.

\section{Wages and Employment}

While the government is not directly responsible for bargaining, it can have a significant effect on wage rates by adjusting statutory minimum wage rates; promoting the living wage amongst employees directly employed and contracted to government agencies, by supporting pay equity settlements, and supporting collective bargaining. Significant pay increases were achieved by unions after successful collective bargaining and pay equity campaigns in state provided and/or funded services in education, health, and public services. Taken together, these have had a significant impact on wages and, in the year to March 2019, reversed the trend of a declining share of the nation's income received by wage and salary earners since 2009 . At the same time as rising wages, pre-Covid-19 unemployment levels shrank to levels not seen since the Clark Government. See Rosenberg (2017b).

\section{State Sector Pay Equity Settlements}

The government has worked closely with the CTU and state sector union affiliates and coordinated the advancement of pay equity settlements during this term and in the shadow of and ahead of the new legislation. State Services Minister, Chris Hipkins, co-led a joint CTU/Ministerial oversight committee which has supported the progression of important settlements in public service, education and health, as well as developed additional resources to assist future claims across the state sector, including occupations funded by the state sector. In addition, the CTU and state sector affiliates have successfully agreed on a set of Gender Pay Principles to support better promotion and advancement of women at work in the public sector.

\section{Migration}

The incoming government inherited a migration system largely geared towards providing a continuing supply of temporary low wage labour to industries unable or unwilling to offer sufficient training and conditions of employment to attract New Zealand residents. The government consulted with business and unions on changes to the process for work visa applications and has introduced a new system that will facilitate more streamlined approvals for jobs where there are genuine skills shortages, while also requiring employers to demonstrate ongoing commitment to the training and recruitment of New Zealand residents.

The CTU has strongly advocated for a shift to a migration system that delivers positive employment outcomes for both migrant and resident workers, with opportunities for migrants to become residents if they choose. We all benefit from the diversity of cultures and skills that migrants bring to our society and it is important that migrants also have a positive experience of their time working in New Zealand. 
The CTU has been clear that we support equal rights for all migrant workers and will not tolerate exploitation of any kind. Unlike previous administrations, this government has recognised the scale of the problem of migrant exploitation and has taken steps to introduce greater protections for migrants facing abuse of their rights at work. However, despite moves in the right direction, the biggest barrier to exploited migrants seeking help remains the fact that temporary work visas are tied to an individual employer. While the government has promised further action to make it easier for migrants to leave an exploitative employer, the CTU has called for more systematic change to detach work visas from specific employers.

\section{What we would have liked to have seen more of....}

\section{Industrial Democracy}

Unlike the previous two Labour-led governments, and despite strong encouragement from the CTU, the Coalition Government provided zero resource or policy support for furthering industrial democracy. The only flicker of activity promoted was WorkSafe's policy of worker participation in health and safety, as a fundamental pillar of a successful health and safety system. In contrast to European and Scandinavian countries, worker and union voice in the New Zealand workplace is sadly lacking, and a command and control management culture generally prevails. Government support to establish worker participation systems and training for union representatives is badly needed to achieve a meaningful change to a more respectful and dignified workplace culture. There are existing models that were developed under the Key Government, such as the successful high performance, high engagement model at KiwiRail, and the efforts at Air New Zealand, along with the long standing traditions of union and worker engagement in the health and public sectors. But the Coalition Government did not seem interested in this core progressive union policy.

\section{State Sector Exemplar}

The CTU has invited the Coalition Government to adopt a policy of making the state sector an exemplar of best employment relations practice. Drawing on the advantages of scale, union presence, and a shared commitment to high quality state sector service delivery, the CTU and state sector affiliates have proposed that a deliberate and shared plan be developed to make the state sector better to work in and better at service delivery. While still on the table, this has yet to progress in any coherent and meaningful way.

\section{Welfare Expert Advisory Group}

The CTU has welcomed the $\$ 25$ weekly increase in main benefits, the Winter Energy Payment, the indexing of main benefits to wages and the recent Covid-19 Income Relief Payment. However, such initiatives barely scratch the surface of the inequities of the welfare system as set out by the Welfare Expert Advisory Group (WEAG). Benefits need to rise and be assessed on an individual rather than a household basis. All of which are the basis of the Covid-19 Income Relief Payment for those who lost their jobs between 1 March and 31 October 2020. The CTU would like to see this approach extended to all people, who, for no fault of their own, find themselves needing support. 


\section{Tax Policy}

Like welfare, tax is a continual disappointment to us. As well as not implementing the Tax Working Group's flagship recommendation of taxing more capital gains, all the recommendations to improve collection, remove loopholes and tighten administration have been overlooked. However, the business-friendly recommendations have been enacted, meaning that workers within the PAYE system continue to be the ones that are relied on to maintain the tax take. We are left with a very weak progressive tax system which is incapable of raising the revenue needed for sound government services and redistribution of incomes.

\section{Capacity and Capability of the Regulators}

An ongoing concern for unions is the lack of capacity and capability of the Labour Inspectorate and WorkSafe inspectors. The previous government had a broad policy in the public sector of 'doing more with less', which of course was simply doing less. They dissolved the Department of Labour and transferred those responsibilities into the newly formed Ministry of Business, Innovation and Employment (MBIE), which had a mantra of 'engage don't enrage' business. Even with the Pike River tragedy exposing a severe lack in the Inspectorate, it has taken too long to restore effective regulation. The paucity of labour and WorkSafe inspectors on the ground is exposed still further when large events like Whakaari White Island eruption place a huge strain on agencies. Agencies are forced to concentrate on getting the biggest bang for buck, which seems to manifest in a focus on softer preventative measures, rather than inspections and prosecutions

An equivalent concern is the reduction in the investigation capacity of the Inland Revenue Department (IRD). The Business Transformation Project at the IRD has seen a greater emphasis on processing and servicing with an equivalent drop in funding for investigation. While the CTU supports the people of New Zealand receiving greater information about their obligations, we are concerned that this is coming at the cost of investigation and enforcement.

\section{Looking Ahead}

\section{Legislation}

Covid-19 got in the way of passing important legislation. Plenty of work has been done on the 'Hobbit Law' amendment, the Holidays Act amendment, and the introduction of Fair Pay Agreements. We would expect that legislation on these areas is completed without delay unless there is a significant change in government.

The CTU has a more ambitious legislative agenda than simply finishing off changes in train. On pay equity, we want to see law requiring pay transparency. We need to do much more than just implement Fair Pay Agreements and pay equity to provide workers with easier access to union membership. Requiring workers to opt out, instead of the current opt in, where a position is covered by an existing collective agreement would be a good start. There are a host of current statutory minimums that can and should be improved, including sick and annual leave provisions. At the same time, support for displaced workers is urgent in the form of introducing a model of social unemployment insurance, redundancy and implementing the WEAG recommendations. The ACC (Accident Compensation Corporation) needs reform to restore 
entitlements removed by the previous government and to cover all forms of occupational health.

\section{Procurement}

The state has enormous buying power, and the CTU would like to see procurement used as another lever to promote good work and positive employment practices. Too often, procurement in both central and local government takes the form of crude tendering, whereby the lowest bid (which often includes lowest wages, and lowest quality) wins the tender. In the absence of national standards, and only the statutory minimums in place, wages and conditions have suffered. The government has begun thinking about procurement more strategically, a move strongly supported by the CTU. Our interest is in ensuring outsourcing is only used where there is clearly a benefit over direct provision and that, when changes in employer occur due to a change of provider, there is no loss of job or conditions in the transfer. There is also an opportunity to insist that those winning contracts for service are compelled to uphold certain standards of employment and be expected to train our workforce for the future. Finally, we want to see tenderers bidding to be of 'good character' and those who have a record of no regard for labour and human rights should be excluded.

\section{Pay Equity}

With the new legislation in place, Unions will be pushing hard to maximise the opportunity to raise and settle pay equity claims. Great progress has already been made in the state and statefunded sector, and now a greater focus will come about in the private sector. Unions will want support from the government to provide resources in terms of analysis of the labour market to identify inequities, as well as information and support. The new legislation will be subject to a review if it does not deliver an appropriate framework in practice.

\section{Conclusion - Covid-19 and beyond}

The statements by the Prime Minister, Jacinda Ardern, and Finance Minister, Grant Robertson, regarding their willingness to pump the economy in order to preserve jobs, and the approach of going 'hard and early', putting health as the key priority, instead of the flawed strategy of focussing on the economy first and foremost, has been supported strongly by the CTU. The various leave and wage support schemes, as immediate measures in response to the pandemic, have also had our strong support.

However, looking ahead at the longer term, we are keen to see a more strategic and fundamental shift in our policy settings. Drawing on the principles we have taken into the Future of Work and the Just Transition work, the CTU is looking for government leadership to take New Zealand toward a high-wage, high-skill, high-productivity, and low carbon economy. That is not easy and involves pushing back against the well-organised business lobby that wants everything put back together the way it was. That would only lead us back to too many people working in low-pay, low-skill jobs in industries that do not create high-value or preserve the environment. The CTU wants to continue the industry planning approach that begun in the Future of Work forum, to begin a real transformation in our industries, and to the way we do business, which is more inclusive, where the costs of transition are shared along with the profits, and the quality of work is a top priority. 


\section{References}

CTU. (2015). Submission of the New Zealand Council of Trade Unions Te Kauae Kaimahi to the Labour Party Future of Work Commission on the Future of Work. https://www.union.org.nz/wp-content/uploads/2017/10/160216-The-Future-ofWork.pdf

Fair Pay Agreements Working Group. (2018). FAIR PAY AGREEMENTS Supporting workers and firms to drive productivity growth and share the benefits. Ministry of Business Innovation and Employment (MBIE). https://www.mbie.govt.nz/assets/695e21c9c3/working-group-report.pdf

Film Industry Working Group. (2018a). Terms of Reference - Film Industry Working Group. Ministry of Business Innovation and Employment (MBIE). https://www.mbie.govt.nz/assets/695e21c9c3/working-group-report.pdf

Film Industry Working Group. (2018b). New Zealand's screen industry: Great work, great workers, Recommendations of the Film Industry Working Group to the Government. Ministry of Business Innovation and Employment (MBIE). https://www.mbie.govt.nz/assets/4c8ac9afb6/recommendations-of-film-industryworking-group-to-government.pdf

Future of Work Tripartite Forum. (2019). Strategic Assessment Priorities for New Zealand's Future of Work.https://www.treasury.govt.nz/sites/default/files/2019-11/fow-forumaug-4204590.pdf

ILO. (2019). Work for a Brighter Future - Global Commission of the Future of Work. ILO. https://www.ilo.org/wcmsp5/groups/public/---dgreports/--cabinet/documents/publication/wcms_662410.pdf

Nana, G. (2019). M4KING SEN5E OF 7HE NUMBERS, Sector Wage Bargaining - a literature review (Reference No: \#5938). BERL. https://www.union.org.nz/wpcontent/uploads/2019/06/Sector-wage-bargaining-Pipiri-2019.pdf

OECD (2017), OECD Employment Outlook 2017, OECD Publishing, Paris, https://doi.org/10.1787/empl_outlook-2017-en.

OECD (2018), Good Jobs for All in a Changing World of Work: The OECD Jobs Strategy, OECD Publishing, Paris, https://doi.org/10.1787/9789264308817-en.

Rosenberg, B. (2017a). Shrinking portions to low and middle-income earners: Inequality in Wages \& Self-Employment 1998-2015. New Zealand Council of Trade Unions Te Kauae Kaimahi. http://www.union.org.nz/wage-and-salary-earners-below-theaverage-wage-lost-out-on-income-growth/inequality-wages-self-employment-1998$\underline{2015 /}$

Rosenberg, B. (2017b). A brief history of labour's share of income in New Zealand 1939-2016. In G. Anderson (Ed.), Transforming Workplace Relations. Victoria University Press. https://www.researchgate.net/publication/317868928_A_brief_history_of_labour\%27 s_share of income_in_New_Zealand_1939-2016 